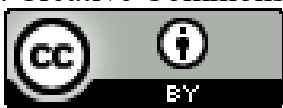

\title{
HOMOSSEXUAIS NEGROS NA(S) HISTÓRIA(S) DO PÓS- ABOLIÇÃO NO BRASIL: ALGUMAS PROVOCAÇÕES À LUZ DO DEBATE SOBRE AS MASCULINIDADES NEGRAS
}

Resumo: O presente artigo constrói-se como uma provocação a partir de uma visita a bibliografias sobre o Pós-Abolição, a História Social da Homossexualidade no Brasil e os debates sobre masculinidades negras no Brasil. Visitando esses três arcabouços, questiono como é possível pensar, a partir destes, as trajetórias de homossexuais negros no Brasil pensando a partir das representações sócio-historicamente construídas sobre sujeitos negros e/ou homossexuais sobretudo nos discursos médico-legais e nas formulações acadêmicas

Palavras-chave: homossexualidade, negritude, interssecionalidade

\section{BLACK HOMOSSEXUALS IN THE BRAZILIAN POST-ABOLITION HISTORIES: SOME PROBLEMS IN THE LIGHT OF BLACK MASCULINITY'S DEBATE}

\begin{abstract}
This article is built as a provocation from a visit to post-abolition historiographies, the Social History of Homosexuality in Brazil and the debates about black masculinities in Brazil. Visiting these three frameworks, I question how it is possible to think, from these, the trajectories of black homosexuals in Brazil thinking from the socio-historically constructed representations about black and / or homosexual subjects, especially in medical-legal discourses and academic formulations
\end{abstract}

Keyword: homosexuality, blackness, intersectionality

\section{NEGROS GAYS EN LA(S) HISTORIA(S) DEL POST-ABOLICIÓN: ALGUNOS PROBLEMAS A LA LUZ DE DEBATE SOBRE LAS MASCULINIDADES \\ NEGRAS}

Resumen: Este articulo se construye como una provocación desde una visita a la bibliografias acerca de la historia del periodo posterior a la abolición, la Historia social de la homosexualidad en Brasil y los debates acerca de las masculinidades negras en

1 Mestrando no Programa de Pós-Graduação em Antropologia da UFF. O presente trabalho apresenta discussões previamente desenvolvidas por ocasião do Trabalho de Conclusão de Curso na graduação em História na Universidade Federal Fluminense. E-mail: victor.paiva@live.com 
Brasil. Al visitar estos tres marcos, me pregunto cómo es posible pensar, a partir de ellos, las trayectorias de los homosexuales negros en Brasil, pensando las representaciones sociohistóricamente construidas sobre sujeitos negros y homosexuales, especialmente en los discursos medico-legales y en las formulaciones academicas.

Palabras-clave: homosexualidade, negritud, interssecionalidad

\title{
NOIR GAYS DANS LE(S) POST ABOLITION HISTORY(S) AU BRÉSIL: THOSE PROBLEMENTS IN THE LUMIÈRE OF DEBAT SUR LE HOMME NOIR
}

Résumé: Cet article est conçu comme une provocation tirée d'une visite de bibliographies post-abolition, de l'histoire sociale de l'homosexualité au Brésil et des débats sur les masculinités noires au Brésil. En visitant ces trois cadres, je me demande comment il est possible de penser, à partir de ceux-ci, les trajectoires des homosexuels noirs au Brésil, en se basant sur des représentations construites de manière sociohistorique sur des sujets noirs et / ou homosexuels, en particulier dans les discours médico-légaux et les formulations académiques.

Mot-clé: homosexualité, noirceur, intersectionnalité;

\section{INTRODUÇÃO}

\begin{abstract}
Todos os movimentos, incluindo o dos negros, lutam pela justiça social e por uma redistribuição equitativa do produto coletivo. Numa sociedade hierarquizada como a brasileira, todos encontram dificuldades para mobilizar seus membros em torno da luta comum para transformar a sociedade. Os movimentos operários ainda não conseguiram mobilizar todos os seus membros, vítimas das relações de trabalhos e de produção dentro da sociedade capitalista, ainda menos no seio de um capitalismo periférico, de escassa cidadania como o brasileiro. Os movimentos feministas terão de lutar muito tempo ainda para tirar milhões de mulheres dos lugares e posições a elas predestinados pelas culturas machistas de todas as sociedades humanas. Os movimentos homossexuais terão de percorrer uma longa caminhada para conseguirem a legitimidade e direitos iguais aos das uniões heterossexuais, consideradas como as únicas e normais, em todas as culturas e de suas respectivas religiões e visões de mundo. (...) Mas se o ditado "a união faz a força" é tão velho quanto a própria humanidade, de onde provém as dificuldades encontradas por esses movimentos? (MUNANGA, 1999, p. 13).
\end{abstract}

O que significa ser homossexual e negro no Brasil? Essa é a pergunta que tem norteado os meus interesses acadêmicos e, em verdade, a minha vida. Como um homossexual negro do pós-abolição, tenho me perguntado sobre o meu lugar no mundo e levo essas questões ao passado nesse processo que configura o fazer historiográfico, o ofício do historiador (BLOCH, 1949). 
Atualmente nos ambientes de militância uma das questões centrais nos debates é o "lugar de fala". Alvo de muitas controvérsias, sua ideia central me parece ser aquela apontada pelo historiador George Fredrickson, de que "[...] uma das tendências mais saudáveis do pós-modernismo é a chamada para os historiadores e outros scholars para serem mais francos sobre o lugar de onde eles vêm, autobiograficamente e ideologicamente, ao invés de assumir uma objetividade Olímpica" (FREDRICKSON, 1997 apud PEREIRA, 2003, p. 12).

Existe uma frase que, arriscamos dizer, todo homossexual negro já ouviu na vida: “Além de preto, é viado?". Essa pergunta nos deixa entrever a percepção social construída acerca da negritude e da homossexualidade. A expressão "além de" poderia ser substituída por "como se não bastasse...", dando a ideia de que ser negro, ou preto, já seria ruim o suficiente e para além disso o interlocutor ainda seria homossexual, agravando o quadro.

Essa ideia da inferioridade e do caráter negativo conferido à negritude e a homossexualidade não é de maneira nenhuma uma surpresa e é, em verdade, até quantificável. Segundo informações do Atlas da Violência para o ano de 2017, a cada 100 assassinatos ocorridos no Brasil, 71 vítimas são negras, tendo os sujeitos negros um percentual de $23,5 \%$ a mais de chances de serem mortos. Ainda de acordo com o documento:

Foi constatado que em todas as Unidades da Federação, com exceção do Paraná, os negros com idade entre 12 e 29 anos apresentavam mais risco de exposição à violência que os brancos na mesma faixa etária. Em 2012, o risco relativo de um jovem negro ser vítima de homicídio era 2,6 vezes maior do que um jovem branco (CERQUEIRA, LIMA, BUENO, VALENCIA et al., 2017, p.30-31).

Já sobre a violência contra LGBTIs, os dados do relatório Grupo Gay da Bahia apontam que no ano de 2016 cerca de 173 homens gays foram assassinados, num total de 343 LGBTIs que foram mortos. Desses 173 homossexuais, 88 foram identificados como brancos, 44 como negros (pretos e pardos) e 40 não tiveram sua "cor" (segundo o critério do gráfico) informada (GRUPO GAY DA BAHIA, 2016). Dessa maneira podemos perceber que indivíduos que "além de pretos, são viados" são ainda hoje corpos expostos à violência, alvos do racismo e da homofobia que permeiam nossa sociedade. 
Não é só através de dados sobre violência física e assassinato, porém, que podemos perceber a maneira nefasta pela qual o racismo brasileiro, ou seja a crença de que uma "raça", a branca, é superior, opera. Segundo a ONG Oxfam, que se utilizou de dados do Ipea e do Pnad para o ano de 2013, os brancos recebem o dobro da renda dos negros. Ainda de acordo com as pesquisas, enquanto que menos de $45 \%$ dos brancos recebem até 1,5 salário mínimo, entre os negros a porcentagem aumenta para cerca de 67\%. Em relação à empregabilidade, muitos homens e mulheres negras reclamam até hoje em dia da dificuldade de conseguirem ser aprovados em entrevistas de emprego e pululam notícias que denunciam observações e comentários feitos sobre cabelos crespos, "black powers" e penteados "afros" no ambiente de trabalho.

Quanto mais escuros e quanto mais traços negroides possuírem, quanto mais “indisfarçável” for sua negritude (MUNANGA, 2008) sobre estes recai uma ideia de sujeira, inadequação, desarrumação e desleixo, o que nos remete às reflexões da antropóloga Mary Douglas em "Pureza e Perigo", em que afirma que "Tal como a conhecemos, impureza é essencialmente desordem", acrescentando em seguida que "A impureza absoluta só existe aos olhos do observador". A impureza seria, portanto, algo que desorganiza, que prejudica e que deve ser extirpado (DOUGLAS, s/d, p.6).

Refletindo com base na teoria de Douglas acerca dos estatutos de limpeza de sangue do século XVIII, a historiadora Larissa Viana nos diz que "Neste caso, o impuro poderia ser visto como ou alguém que não está em seu lugar, e não deve ser incluído se há o imperativo de manutenção de uma determinada ordem social" (VIANA, 2016, online). O mesmo ocorre com os homens homossexuais, sobretudo conforme eles fogem à heteronormatividade, ou seja, ao padrão heterossexual de comportamento social, e são identificados como "afeminados". Definindo a homofobia, Daniel Borrillo afirma que se trata da ideia de que a homossexualidade é o caminho natural e a homossexualidade um desvio, o que confere, por consequência, à primeira um caráter de superioridade enquanto a segunda se torna inferior (BORILLO, 2015, p. 17).

\section{HISTÓRIA E HISTORIOGRAFIA DO PÓS-ABOLIÇÃO}

O que pretendemos com essa designação? Que marcos poderiam ser estabelecidos? A persistência de estigmas e desigualdades ligadas à memória da escravidão está, sem dúvida, no centro da resposta à questão. (...) destacamos o

Revista da ABPN • v. 11, n. 30 • set - nov 2019, p.152-173 
caráter inconcluso da implementação da cidadania e da igualdade após a conquista do fim da escravidão, assim como a permanência e recriação de mecanismos de hierarquização, discriminação e exclusão racial. Ainda que em um longo processo de muitas especificidades, no contexto das abolições nas Américas, a escravidão atlântica se definiu como uma escravidão racial nos diferentes países ou regiões marcados pela diáspora forçada de africanos escravizados. Podemos afirmar que o interesse maior (...) concentra-se na investigação sobre os processos de racialização ligados a memória da escravidão em seus aspectos econômicos, econômicos, políticos, sociais, identitários, culturais e educacionais. (ABREU; DANTAS; MATTOS, 2014, p. $1)$.

O "pós-abolição como problema histórico" foi proposto pelas historiadoras Hebe Mattos e Ana Lugão Rios, que em artigo publicado em 2004 questionavam a historiografia que se dedicava ao período para quem, segundo as autoras, "Os últimos cativos e seu destino após a abolição atraíam compaixão e simpatia, mas não pareciam apresentar maior potencial explicativo para a história do período”. Mattos e Rios afirmam ainda que "Com a abolição do cativeiro, os escravos pareciam ter saído das senzalas e da história, substituídos pela chegada em massa dos imigrantes europeus" (MATTOS; RIOS, 2004).

É interessante observarmos que esse momento historiográfico analisado por Mattos e Rios sobre os sujeitos negros após a abolição, sua dita "saída da senzala e da história", é muito similar ao projeto empreendido pela intelectualidade local e pelo Estado brasileiro na segunda metade e sobretudo ao final do século XIX, onde havia a ideia de que as falhas e os atrasos do país seriam explicados por uma "miscigenação negativa", na qual a população progressivamente se tornava mais escura, "mulata". A solução seria, portanto, uma "miscigenação positiva", em que paulatinamente a população se embranqueceria, operar-se-ia, portanto, a "Redenção de Cam", como propunha o quadro de Modesto Brocos (1895). A intelectualidade brasileira realizava um movimento de "antropofagia" das teorias cientificas racistas que vinham da Europa, bem como das observações de viajantes estrangeiros, adaptada à realidade brasileira (SCHWARCZ, 1994, online.) 
Esse impulso pela imigração europeia, organizado enquanto política de Estado, culminou com a vinda de cerca de 4 milhões de trabalhadores europeus num período de quatro décadas, números equivalentes ao do tráfico de africanos ao Brasil que perdurou três séculos (BENTO, 2002, p.32 apud PEREIRA, 2010, p. 64)

Em trabalho clássico, "A Abolição", a historiadora Emilia Viotti da Costa discute a liberdade dos sujeitos negros com o fim da escravidão a partir da análise das memórias de Gregório Bezerra (1980), que contam a história de um homem negro que trabalhava como feitor em uma fazenda e afirmava, uma vez livre, ter saudades da escravidão, época na qual, segundo ele, tinha melhores condições de sobreviver e se alimentar. Como nos diz a autora

Fruto do desespero de um homem que "depois da abolição fora abandonado à sua própria sorte, sem que a sociedade lhe assegurasse mínimas condições de vida", esse depoimento de um escravo que tinha saudades da escravidão não deve ser entendido como um comentário a favor da escravidão. Ele é, de fato, um testemunho eloquente das condições de vida em que se encontraram muitos ex-escravos, para os quais a abolição representara apenas o direito de ser livre para escolher entre a miséria e a opressão em que viveu (e ainda vive) grande número de trabalhadores brasileiros. (COSTA, 2010, p.60).

Desse modo, à semelhança do que houve em certo momento da historiografia, houve uma ênfase e estímulo à presença dos imigrantes no Brasil sobretudo após a abolição do cativeiro e no início do século XX e um "esquecimento" dos sujeitos negros, agora livres, mas em situação de "quase-cidadania" (CUNHA; GOMES, 2007) numa (re)inserção marginalizada à sociedade sem qualquer tipo de reparação ou indenização. Sabemos, porém, que não se trata de uma falha do projeto do Estado e sim de um projeto de genocídio demográfico, historiográfico e epistemológico da população negra que passa, sem dúvidas, pela ideia de branqueamento e pela complexidade do racismo, que se configura enquanto um "crime perfeito" para o antropólogo Kabengele Munanga (REVISTA FÓRUM, 2014).

Neste sentido, abordando a dimensão teórica e metodológica dos estudos sobre pós-abolição, podemos apontar uma virada historiográfica debitária destes que vem cada vez mais se consolidando enquanto campo de pesquisas. Comentando sobre essa produção, Wlamyra Albuquerque afirma:

(...) as pesquisas sobre o pós-abolição viriam a usufruir do empenho academicamente militante dos historiadores da época. O propósito de dar conta das aspirações e formas de resistência dos cativos no campo da história social tornou possível a travessia da

Revista da ABPN • v. 11, n. $30 \bullet$ set - nov 2019, p.152-173 
fronteira dada pela história política institucional, que separava o período imperial/escravista do republicano/trabalho livre" (ALBUQUERQUE, 2010, p. 98).

É importante também que destaquemos a importância da interlocução entre a História e a Antropologia para essa mudança na abordagem do período pós-abolição, que se debruça sobre as histórias e trajetórias dos homens e mulheres negras. Se por um lado, como aponta Maria Regina Celestino de Almeida, a Antropologia imobilizava seus objetos de estudo, não percebendo as nuances temporais e geográficas da(s) cultura(s), a História desprezava em suas análises os hábitos, costumes e simbolismos do cotidiano, sobretudo no que diz respeito aos "grupos marginalizados". Nesse aspecto, a autora, resgatando Peter Burke, demonstra a importância para a ciência histórica a incorporação de leituras antropológicas do conceito de cultura "tanto no sentido malinowskiano como 'artefatos herdados, bens, processos técnicos, ideias, hábitos e valores' - como geertziano - enquanto 'dimensões simbólicas da ação social [...]” (ALMEIDA, 2012, p.153).

O campo do pós-abolição, que vem se consolidando e dando enormes contribuições para a historiografia e para a sociedade se dedica à estudar os libertos e seus desejos, planos e agências no Brasil Republicano. É possível que pensemos em um paralelo entre essa abordagem e aquela da corrente da "história vista por baixo", cujos membros incluem, para ficarmos com dois nomes bastante conhecidos, os historiadores Edward P. Thompson e Natalie Zemon Davis. Para Peter Burke, esses historiadores se debruçavam sobre "[...] as opiniões das pessoas comuns e com sua experiência da mudança social" em contraposição a uma "história tradicional" que fornecia uma "visão de cima" (BURKE, 1992, p. 3).

As perguntas que então se colocam são: $O$ que significa então ser negro nesse contexto? Que papel a raça desempenha nas sociabilidades e nas agências individuais e coletivas? Inicialmente, é importante que destaquemos que quando nós falamos em raça atualmente, esta é entendida não de maneira biológica, interpretação academicamente superada embora ainda encontre algumas sobrevivências no chamado "senso comum" e, sobretudo, nos discursos de grupos racistas, mas enquanto "construções sociais", enquanto abstrações construídas a partir das diferenças observadas entre os seres humanos. "O que são raças para a sociologia, portanto? São discursos sobre as origens de um grupo, que usam termos que remetem à transmissão de traços fisionômicos, 
qualidades morais, intelectuais, psicológicas, etc., pelo sangue (conceito fundamental para entender raças e certas essências)" (GUIMARÃES, 2003, p. 96).

\title{
RAÇA E TEORIAS RACIAIS, SÉC. XIX E XX
}

Kabengele Munanga nos chama a atenção para o fato de que "Como a maioria dos conceitos, o de raça tem seu campo semântico e uma dimensão temporal e especial" (MUNANGA, 2003, p. 1), sendo necessário que atentemos para sua historicidade, sobretudo para as teorias raciais de fins do século XIX que atravessam para o século XX.

Conforme aponta a historiadora e antropóloga Lilia Schwarcz, "raça" começa a aparecer na "literatura especializada" no começo do século XIX, pelas mãos de Georges Cuvier, “(...) inaugurando a ideia de heranças físicas permanentes entre os vários grupos humanos" (SCHWARCZ, 1994, online).

\begin{abstract}
Delineia-se a partir de então certa reorientação intelectual, uma reação ao Iluminismo em sua visão unitária da humanidade. Tratava-se de uma investida contra os pressupostos igualitários das revoluções burguesas, cujo novo suporte concentrava-se na ideia de raça, que em tal contexto cada vez mais se aproximava da noção de povo. $\mathrm{O}$ discurso racial surgia, dessa maneira, como variante do debate sobre a cidadania, já que no interior desses novos modelos discorria-se mais sobre as determinações do grupo biológico do que sobre o arbítrio do indivíduo entendido como "um resultado, uma reificação dos atributos específicos de sua raça (SCHWARCZ, 1994, online).
\end{abstract}

Esse debate acerca das raças tem raízes mais profundas, que remetem, segundo Schwarcz, as discussões acerca da própria origem da humanidade. A autora identifica "duas grandes vertentes": a monogenista e a poligenista. A primeira, como o próprio nome sugere, pressupunha uma origem comum para todos os seres, amparando-se sobretudo nos escritos da Bíblia, tendo sido "dominante até meados do século XIX". Já a visão poligenista suscitava uma interpretação biológica das relações e comportamentos humanos. A criação de teorias tais como a "antropometria" e a "frenologia" teriam ajudado a encorpar e dar mais força à essa interpretação. A isso soma-se também os surgimentos de uma nova craniologia técnica "que incluía a medição do índice cefálico [...]” e de "uma nova hipótese que se detinha na observação 'da natureza biológica do comportamento criminoso'. Era a antropologia criminal, cujo principal expoente - Cesare Lombroso - argumentava ser a criminalidade um fenômeno 
físico e hereditário" (SCHWARCZ, 1994, online). Podemos observar, portanto, a cientificização de um discurso que atrela raça e criminalidade, uma vez que raça era entendida enquanto transmissão de fatores hereditários permanentes e a criminalidade passa, na teoria de Lombroso, a ser considerada um fenômeno hereditário.

Um marco para essa discussão entre monogenistas e poligenistas é a publicação, no ano de 1859, do livro "A Origem das Espécies" pelo naturalista britânico Charles Darwin. Schwarcz afirma que "[...] o impacto da publicação dessa obra foi tal que a teoria de Darwin passou a constituir uma espécie de paradigma da época, diluindo antigas disputas", acrescentando adiante que "As máximas de Darwin se transformavam, aos poucos, em referência obrigatória, significando uma reorientação teórica consensual [...]. O darwinismo forneceu uma nova relação com a natureza e, aplicado a várias disciplinas sociais [...] formou uma geração social-darwinista" (SCHWARCZ, 1994). Ou seja, uma teoria que fora cunhada para explicar o desenvolvimento das espécies animais, transformara-se em arcabouço teórico para análises "social-darwinistas", implicando na importação de conceitos como seleção natural, a ideia de "sobrevivência do mais apto", e evolução para análises acerca das diferenças observadas entre humanos e na esfera do social.

Para Marcos Chor Maio e Ricardo Ventura Santos, o pensamento darwinista acaba consolidando uma visão monogenista, muito embora estabeleça hierarquias entre as raças, estando o branco (caucasiano) no topo e os negros e indígenas nos extratos inferiores (MAIO; SANTOS, 2010)

\begin{abstract}
A partir desse balanço nota-se que a percepção da "diferença" é antiga, mas sua "naturalização" é recente. Ou seja, é apenas no século XIX, com as teorias das raças, que a apreensão das "diferenças" transforma-se em projeto teórico de pretensão universal e globalizante. "Naturalizar as diferenças" significou, nesse momento, o estabelecimento de correlações rígidas entre características físicas e atributos morais. Em meio a esse projeto grandioso, que pretendia retirar a diversidade humana do reino incerto da cultura para localizá-la na moradia segura da ciência determinista do século XIX, pouco espaço sobrava para o arbítrio do indivíduo. Da biologia surgiam os grandes modelos e a partir das leis da natureza é que se classificavam as diversidades (SCHWARCZ, 1994, online).
\end{abstract}

Na segunda metade do século XIX e no início do XX, os debates sobre raça mobilizaram estudos e interpretações de intelectuais das mais diversas áreas de tão imbricada que a questão racial estava em todos os aspectos da vida social. A 
antropóloga Giralda Seyferth afirma que "[a] ideia de raça construída sobre hierarquia denotando desigualdade dominou o pensamento social em muitos lugares, inclusive no Brasil” (SEYFERTH, 1996, p. 43 apud PEREIRA, 2010, p. 63).

Segundo o historiador Amilcar Pereira, a questão da raça apresentava-se, desde o século XIX, como ponto nevrálgico da discussão sobre nação e nacionalidade. Essa característica, como nos diz o autor, gera uma contradição interna, a saber:

(...) tendo em vista a enorme influência das teorias raciais do século XIX (...) como construir uma identidade nacional - naquele momento ligada diretamente à ideia de raça que se constituía - com uma população cuja maioria descendia de ex-escravizados de origem africana e indígenas, considerados inferiores? (PEREIRA, 2010, p. 63).

Segundo as historiadoras Germana Guimarães e Solange P. Rocha, a construção de uma identidade nacional, de uma "brasilidade" se pôs em curso, sobretudo a partir da década de 1870 a partir do "reconhecimento da figura do indígena, do africano do europeu e do mestiço, apesar da existência das diferenciações sobre eles com a dicotomia superioridade versus inferioridade" (GUIMARÃES; ROCHA, 2016, p. 236). Como afirma Rodrigo Reduzino:

O conceito de nação moderna não é uma resultante de um processo social estático; ele é um processo contínuo, conjuntural, histórico e temporal e nele existem mediações políticas e disputas teóricas/políticas na sua formação, se tornando um espaço de poder simbólico ou de campo30 de poder, como o poder de quem pode enunciar, descrever, falar, conferindo status à relação (REDUZINO, 2016, p. 28).

Os debates sobre nacionalidade brasileira, bem como as teorias raciais e a política do embranquecimento empreendida pelo Estado, atravessaram do século XIX para as primeiras décadas do século XX, influenciando a jovem República e a maneira através da qual eram enxergados os sujeitos negros nesse contexto. Olívia Maria Gomes da Cunha demonstra, no artigo "1933: um ano em que fizemos contato" as conexões entre a produção intelectual e científica e a atuação policial,

[...] a informar práticas de prevenção e repressão criminais, a partir das quais se imaginava possível identificar, criminalizar e punir certos indivíduos através da crença de que seus caracteres biológicos frente às adversidades - sociais e climáticas determinavam comportamentos anti-sociais (CUNHA, 1995, pp. 145-146). 
Nesse sentido, fica demonstrada a influência das teorias raciais, informando a ação das instituições públicas, sobretudo da polícia, que, a um só tempo, racializava e criminalizava os sujeitos não-brancos.

\section{SOBRE A HOMOSSEXUALIDADE}

Diversos são os estudos nas Ciências Humanas sobre a homossexualidade no Brasil, seja do ponto de vista dos sujeitos, cujas nomenclaturas navegaram historicamente entre "sodomitas", "fanchonos", "invertidos" "pederastas" entre outras, seja na perspectiva dos discursos médico-legais construídos acerca destes. Segundo Magali Engel, existem

(...) duas possibilidades mais importantes para as abordagens da sexualidade como objeto da história, cada uma das quais profundamente diversificada, comportando uma série de matizes. O primeiro caminho orienta-se no sentido de uma história dos discursos sobre o sexo, no qual Foucault representa um marco fundamental, questionando, entre outras coisas, o caráter puramente repressivo de tais discursos. $\mathrm{O}$ outro caminho aponta para uma história das vivências e do cotidiano da sexualidade, priorizando o estudo dos comportamentos reveladores dos variados usos do corpo (ENGEL, 1997, p. 431).

Como nos diz Matheus Rodrigues Pinto (2015, p. 13), somente a partir da década de 1960, que marca, em suas palavras, "a gênese do movimento gay organizado", a historiografia dedicou-se com fôlego e afinco à história da homossexualidade, seja "no campo do erotismo" ou na questão da "identidade cultural de indivíduos e grupos". Trabalhos pioneiros com os de Luiz Mott, Peter Fry, Carrara e Simões, apenas para ficarmos entre alguns autores, lançaram importantes bases para futuras análises.

Segundo Lucas Freire, para os cristãos os sodomitas eram encarados como pecadores, sendo criminalizados pelas Ordenações Portuguesas Afonsinas, Manuelinas e Filipinas. Essas últimas foram implementadas em 1603 e duraram cerca de dois séculos, tendo sido adaptadas à Constituição de 1824 (FREIRE, 2012, p. 89). No século XIX, porém, a visão acerca da homossexualidade é modificada, o que inclui a sua “[...] descriminalização e o surgimento de um novo campo do saber no estudo da homossexualidade" (FREIRE, 2012, p. 90). 
Com este cenário, a homossexualidade passou a ser designada pelo termo homossexualismo. Deste modo, as relações sexuais entre pessoas do mesmo sexo adquiriram um caráter patológico, pois, desviam-se da única expressão sexual apontada como útil: a heterossexualidade. Não tão diferentemente da religião, a ciência pautava seus resultados no discurso da reprodução e da diferenciação incomensurável entre os sexos (LAQUEUR, 2001). Surge então o termo homossexual, cunhado pelo médico Karl Maria Kartbeny em 1869 (TREVISAN, 2011, p. 178) [...] Desta forma, o homossexual não podia mais ser comparado ao sodomita, pois, este era um pecador/criminoso e aquele um doente mental/anormal, incapaz de controlar seus impulsos. Como consequência dessa mudança de paradigma, houve a descriminalização da prática homossexual. Tal processo teve como ponto de partida o encerramento das atividades do tribunal do Santo Ofício em 1821, e se concretizou com a entrada em vigor do Código Criminal de 1830, que não mais previa o crime de sodomia, desde que acontecesse entre adultos consentidos e sem incidência pública (FREIRE, 2012, p. 9091).

Agora objeto da medicina, a homossexualidade torna-se uma questão de saúde pública que suscita a intervenção do Estado, "através de higienistas, médicos-legais e psiquiatras, o controle estatal atingiu seu apogeu" (FREIRE, 2012, p. 91). Tratado pelo jargão científico de uranismo, cunhado pelo jurista alemão Karl Heinrich Ulrichs, o tema também é bastante discutido no Brasil, por nomes como Pires de Almeida, Leonídio Ribeiro e Aldo Sinisgali (FREIRE, 2012, p. 91).

No Brasil, em meados de 1930, após a posse de Getúlio Vargas, Leonídio Ribeiro, que pertencia à Faculdade de Medicina, fora nomeado pelo chefe da polícia Baptista Luzardo para a direção do Instituto de Identificação da Polícia Civil do Distrito Federal. Entre suas ações, Ribeiro organizou a criação do Laboratório de Antropologia Criminal onde desenvolvia diversos estudos sobre criminalidade à luz do pensamento Lombrosiano. Leonídio Ribeiro, inclusive, recebe, no ano de 1933, um prêmio conferido pela Academia Italiana de Medicina por suas pesquisas, entre as quais uma que versava sobre "biótipos criminais afro-brasileiros" e outra sobre "relações entre a homossexualidade masculina e o mal-funcionamento endócrino" (GREEN, 2000). É interessante notarmos que suas pesquisas se focam nos grupos socialmente marginalizados como afro-brasileiros, homossexuais e indígenas.

Ribeiro recebeu importante auxílio do oficial de polícia Dulcídio Gonçalves para a realização de seus estudos, que consistiu em levar ao Laboratório de Antropologia Criminal, 195 "homossexuais profissionais”, cuja definição não é conhecida mas Green supõe que se trate de "homens que dedicavam muito do seu tempo livre para procurar parceiros sexuais, ou que suas vidas gravitavam em torno de seus desejos eróticos" (GREEN, 2010), para pesquisas. 
Sobre Leonídio Ribeiro, afirma Lucas Freire:

Leonídio Ribeiro, médico formado na Faculdade de Medicina do Rio de Janeiro e fundador do Laboratório de Antropologia Criminal do Instituto de Identificação do Rio de Janeiro, teve como principais inspirações as teorias dos médicos europeus Gregório Marañón[5] e Cesare Lombroso [6], como apontado por Green e Polito (2006). Pautado na teoria de origem endocrinológica da homossexualidade de Marañón, ele propôs um modelo de intervenção baseado no transplante de testículos para corrigir as falhas do organismo na produção de hormônios masculinos. Só assim o uranista poderia se transformar em um homem de verdade. Foi também Leonídio Ribeiro o responsável por um dos mais extensos levantamentos de características biotipológicas de homossexuais do país (FREIRE, 2012, p. 92).

Essa relação entre a polícia e a homossexualidade remonta, de alguma forma, a meados XIX, quando, segundo Luiz Mott (2006), com o fim do Tribunal do Santo Ofício da Inquisição, em 1821, responsável pela morte de diversos indivíduos considerados culpados pelo "pecado nefando", houve um processo de "medicalização da homossexualidade" em que "[...] não mais os padres, mas os delegados de polícia passaram a reprimir os infelizes, a que chamavam de 'pederastas', sob alegação de atentado ao pudor e aos bons costumes" (MOTT, 2006, p.510). O sujeito homossexual, classificação esta que surge também nesta época em 1869, deixa, portanto, de ser assunto da Igreja Católica e da religião, embora siga sendo condenado segundo leituras bíblicas, e passa a ser "caso de polícia".

Para o caso das décadas de 20 e 30 no Brasil, James Green chama a atenção para o fato de que a intervenção do Estado, da polícia e dos diversos estudiosos que se debruçaram sobre a vida e o comportamento dos homossexuais era respaldado pela tradição positivista brasileira, que acionava a ciência como mantenedora da ordem social (GREEN, 2000).

Segundo Rodolfo Tavares, em pesquisa sobre os discursos médico-legais produzidos acerca dos homossexuais e lésbicas entre 1870 e 1935:

Homens homossexuais e mulheres lésbicas não estavam, desta forma, enquadrados na nação por não terem as relações afetivas e sexuais esperadas pela heteronormatividade; não se casarem ou formarem família - e quando a faziam, escapavam para vivenciarem de forma plena a sexualidade; e, por fim, exercerem a prostituição ou profissões que não lhes cabia ao gênero. Assim, a homossexualidade e a lesbianidade aqui analisadas nos discursos médico e jurídico eram despidas e esculpidas com o fim de corrigí-las, não de conhecê-las (TAVARES, 2016, p. 55).

\section{DIÁLOGO COM AS MASCULINIDADES NEGRAS}

Revista da ABPN • v. 11, n. $30 \bullet$ set - nov 2019, p.152-173 
No ano de 1851, a ex-escravizada Sojourner Truth proferiu em convenção de mulheres, um célebre discurso, posteriormente entitulado “Ain't I A Woman?” em que questionava o imaginário e os olhares sobre o que era caracterizado como "mulher" a partir de um tensionamento proveniente de sua própria trajetória que, por ser mulher negra e portanto atravessada pela experiência da racialização, tornava-a não apta a ser enquadrada enquanto uma mulher, nos moldes apresentados.

\begin{abstract}
Aquele homem ali diz que as mulheres precisam ser ajudadas em carruagens e erguidas sobre valas, e ter o melhor lugar em todos os lugares. Ninguém nunca me ajuda em carruagens, ou em poças de lama, ou me dá o melhor lugar! E eu não sou uma mulher? Olhe para mim! Olhe para o meu braço! Eu poderia ter arado, plantado e reunido em celeiros, e ninguém poderia me liderar! E eu não sou uma mulher? Eu podia trabalhar tanto e comer tanto quanto um homem - quando conseguia - e suportar o chicote também! E eu não sou uma mulher? Tenho treze filhos e os vi quase esgotados para a escravidão. Quando gritei com a dor de minha mãe, ninguém além de Jesus me ouviu! E eu não sou uma mulher? (TRUTH, 1851, tradução minha).
\end{abstract}

A partir de comparações entre um modelo idealizado de mulher e a exemplos de sua própria vida, Truth evidencia um abismo entre o que significava "ser mulher", cujo imaginário era sem dúvida o de mulheres brancas, e mulheres negras. Desse modo, a pergunta que faz é, em certo ponto, pertinente: dada essa questão, eram as mulheres negras mulheres de fato? Angela Davis, em sua clássica obra "Mulheres, Raça e Classe", afirma que o discurso de Sojourner Truth, proferido durante a convenção de Akron em Ohio, em que era a única a mulher negra presente ao mesmo tempo que era um confronto ao sexismo, “[...] também era uma resposta às atitudes racistas das mesmas mulheres brancas que posteriormente louvaram sua irmã negra”, acrescentando em seguida o fato de que "Não foram poucas as mulheres reunidas em Akron que inicialmente se opuseram às mulheres negras terem voz na convenção, e os opositores dos direitos das mulheres tentaram tirar vantagem deste racismo" (DAVIS, 2010 [1981], p. 73). Nesse sentido, Sueli Carneiro afirma:

As mulheres negras tiveram uma experiência histórica diferenciada que o discurso clássico sobre a opressão da mulher não tem reconhecido, assim como não tem dado conta da diferença qualitativa que o efeito da opressão sofrida teve e ainda tem na identidade feminina das mulheres negras (CARNEIRO, 2013, p. 1). 
O discurso de Sojourner Truth, bem como as leituras de Angela Davis e Sueli Carneiro, entre outras autoras, apontam para a necessidade de que complexifiquemos nosso olhar sobre os indivíduos e grupos sob pena de não sermos capazes de acessa-los na inteireza de suas trajetórias, sentidos e disputas. Nesse sentido, faz-se mister que lancemos mão da abordagem que ficou conhecida, tanto na academia como nos espaços de militância social, como interseccional. Kimberlé Crenshaw define a interseccionalidade como

[...] uma conceituação do problema que busca capturar as consequências estruturais e dinâmicas da interação entre dois ou mais eixos de subordinação. Ela trata especificamente da forma pela qual o racismo, o patriarcalismo, a opressão de classe e outros sistemas discriminatórios criam desigualdades básicas que estruturam as posições relativas de mulheres, raças, etnias, classes e outras. [...] tais sistemas, frequentemente, se sobrepõem e se cruzam, criando intersecções completas nas quais dois, três ou quatro eixos se entrecruzam. (CRENSHAW, 2002, p. 177).

Ou seja, é preciso que nos atentemos aos múltiplos "eixos de subordinação" que atravessam os sujeitos e se inter-relacionam, modificando-se entre si. No caso de Sojourner Truth, o fato de ser negra altera o sentido do "ser mulher" em sua trajetória, a partir de um processo de racialização. Angela Davis, em discurso na $1^{\text {a }}$ Jornada Lélia Gonzales, afirma, nessa perspectiva que

É preciso compreender que classe informa raça. Mas raça, também informa classe. E gênero informa classe. [...] Precisamos refletir bastante para perceber as intersecções entre raça, classe e gênero, de forma a perceber que entre essas categorias existem relações que são mútuas e outras que são cruzadas (DAVIS, 1997).

Em instigante artigo, Lucas Veiga nos fala da dupla "diáspora" das bixas pretas, que conceitua da seguinte forma:

A saída forçada de África e a vida num país anti-negro são elementos que se entrecruzam na produção da subjetividade negra. A subjugação dos africanos à condição de escravos produziu efeitos devastadores em suas subjetividades. Para além das mortes de africanos nos porões dos navios, nas rebeliões, nos castigos perpetrados pelos colonizadores, muitos africanos em condição de escravidão atentaram contra a própria vida. A retirada forçada de sua terra, de sua comunidade, de sua língua, de seus laços afetivos e a subsequente diáspora pelo mundo na condição de escravos tiveram efeitos de desterro e de perda de referências tão acentuados que a própria identidade e consciência corporal entravam num processo de desintegração. (VEIGA, 2019, p. 81$83)$.

A partir disso e da breve análise histórica e historiográfica aqui promovida, proponho a provocação: como pensar as masculinidades negras de homossexuais 
negros, cujos corpos e subjetividades são interpelados por essas projeções e construções de gênero que são experienciadas de maneiras particulares na interconexão com a (homo)sexualidade. Considerando que, como vimos, a homossexualidade foi encarada sócio historicamente no pensamento médico-legal como um desvio que sugere a propensão ao crime e que os homens negros foram objetos de representações como as de estuprador negro (DAVIS, 2016 [1981], p. 118), interpretados pelo viés da animalização, do comportamento sexual desenfreado que nos remete aos estereótipos circulantes nos territórios da diáspora nas Américas. Notadamente podemos fazer referência à construção da imagem do Mandingo, ou "Black Bucks", que, segundo a historiadora Suzane Jardim, era definido como o negro indomável, de institutos sexuais perigosos que amedontram às pessoas brancas (JARDIM, 2016). Alex Ratts chama a atenção para duas outras personagens que também são construídas e interpretadas nesse viés. Uma é o "Bom Crioulo", personagem-título da obra de Adolfo Caminha, um marinheiro negro que se apaixona por um jovem branco e cujo final é marcado pela tragédia. Amaro, o bom crioulo, é “[...] descrito pelo autor como um 'pedaço de bruto', 'um animal inteiro' [...]” (RATTS, 2007, p.2). O outro é um personagem abordado por James GREEN (2005) chamado "Preto Amaral", “acusado de sedução, estupro e assassinato de um adolescente branco" (RATTS, 2007, p.4). Esses sujeitos habitam portanto, muitas vezes, entre a criminalização e a hiperssexualização, que são muitas vezes faces da mesma moeda manipuladas no discurso genocida e necropolítco (MBEMBE, 2001)

Nos diz Túlio Custódio:

Os debates de masculinidades negras têm uma abrangência de questões. Nesse sentido, trabalham desde a ideia de novas perspectivas de masculinidades a partir dos feminismos negros, até uma visão de masculinidades que conciliam o resgate de uma perspectiva pan-africanista de ser homem negro (RIBEIRO; FAUSTINO, 2017). Esses debates têm dois grandes campos: o público e o acadêmico, que, de uma maneira particular e interessante, se complementam e fortalecem a reflexão sobre o tema no contexto nacional. Em relação ao debate público, ele vem sendo pautado por dois eixos: olhar sobre as questões do genocídio do homem negro e olhar sobre as questões práticas dos homens negros (CUSTÓDIO, 2019, p.136). 
Como aponta Mara Viveros Vigoya, é a partir dos anos de 1970 que emerge nos

Estados Unidos da América o campo dos Men's Studies, a que autores como Michael Kimmel preferiam chamar de "estudos das masculinidades".

\begin{abstract}
Os estudos das masculinidades seguiram basicamente duas orientações distintas: as que se definem como aliadas do feminismo e as que reivindicam uma análise autônoma da masculinidade (Kimmel, 1992). As primeiras analisaram a construção social da masculinidade e têm sido realizados por homens que afirmam seus vínculos com o movimento feminista e os desenvolvimentos da teoria feminista. As segundas foram influenciadas por uma literatura de ampla difusão inspirada no movimento mito-poético surgido ao redor do livro de Robert Bly: Iron John: a book about men [João de Ferro: um livro sobre homens]. A partir dos contos dos irmãos Grimm, Bly descreve o desenvolvimento masculino e a profunda nostalgia que os homens sentem de uma vida com significados e que deixe marcas (VIGOYA, 2018, p. 41-42).
\end{abstract}

Vigoya chama a atenção para a importância da obra da socióloga Raewynn Connell, sobretudo de sua obra seminal "Masculinities", que constitui uma nova abordagem analítica das masculinidades a partir de uma perspectiva que as encara de maneira absolutamente relacional: "Masculinity does not exist except in contrast with femininity” (CONNELL, 1997 68). Para Connell as masculinidades deveriam ser analisadas como integradas "às estruturas de gênero mais amplas" (VIGOYA, 2018, p. 42), "como forma de ordenamento da prática social" (CONNEL, 1997. p. 35 apud VIGOYA, 2018, p. 42).

Connell estabelece o conceito de "masculinidade hegemônica", a partir do conceito de "hegemonia" do filósofo italiano Antonio Gramsci que se refere "à dinâmica cultural na qual um grupo reclama e sustenta uma posição de liderança na vida social". A masculinidade hegemônica seria, em sua definição, "a configuração de uma prática de gênero que incorpora (embodies) a atual resposta ao problema de legitimidade do patriarcado, que garante (ou supõe-se que garante) a posição dominante dos homens e a subordinação das mulheres" (CONNELL, 1997, p. 77). A autora chama a atenção ainda para as ideias de "subordinação", apontando o caso dos homens homossexuais e a maneira como estes tem sido subordinado aos heteros, e de "cumplicidade", que aponta para o fato de que por mais que muitos homens não estejam rigorosamente dentro da masculinidade hegemônica ainda sim lucram material e simbolicamente de privilégios advindos da mesma (CONNELL, 1997, pp.78-80). 
Uma ideia particularmente cara é a de "marginalização", que diz respeito às interfaces entre masculinidades (gênero) e outras dimensões estruturais da sociedade como classe e raça. Segundo Raewynn Connell:

\begin{abstract}
Race relations may also become an integral part of the dynamics between masculinities. In a White-supremacist context, black masculinities play symbolic roles for White gender construction. For instance, black sporting stars become exemplars of masculine toughness, while the fantasy figure of the black rapist plays an important role in sexual politics among whites, a role much exploited by right-wing politics in the United States. Conversely, hegemonic masculinities among whites sustains the institutional oppression and physical terror that have framed the making of masculinities in black communities (CONNELL, 1997, p. 80)².
\end{abstract}

Essas relações entre esses marcadores sociais da diferença como gênero, raça e classe são primordiais para discutirmos "masculinidades negras". Mas como pensar a partir da sexualidade? Como pensar as experiências de homossexuais negros a partir dos debates das masculinidades negras, esfera ainda pouquíssima abordada?

A dinâmica da (hiper)sexualização é uma faceta pungente desse debate, apontada por Mara Vigoya em sua pesquisa sobre masculinidades negras na Colômbia. A autora destaca, a partir de suas entrevistas, a forma como seus interlocutores, jovens negros de "um dos distritos mais pobres do país [Colômbia] e com maior porcentagem de população negra" internalizavam as construções e estereótipos acerca das masculinidades negras como características positivas. Penso, nesse sentido, na contribuição que nos traz a antropóloga Saba Mahmood. Como diz a autora, “[...] o conjunto de capacidades inerentes ao sujeito, ou seja, as capacidades que definem os modos de sua agência não são o resíduo de um self não domesticado, existente antes das operações de poder, mas são, em si mesmas, produto dessas operações” (MAHMOOD, 2006, p. 133). Transformar o estereótipo em qualidade é uma maneira que esses jovens encontram de habitar as normas em que são produzidos. Segundo Mara Vigoya,

2 Tradução: As relações raciais também podem se tornar parte integrante da dinâmica entre masculinidades. No contexto da supremacia branca, a masculinidade negra desempenha papéis simbólicos na construção de gênero dos brancos. Por exemplo, estrelas esportivas negras se tornam exemplos de dureza masculina, enquanto a figura fantasiosa do estuprador negro desempenha um papel importante na política sexual entre brancos, um papel muito explorado pela política de direita nos Estados Unidos. Por outro lado, as masculinidades hegemônicas entre os brancos sustentam a opressão institucional e o terror físico que moldaram a criação de masculinidades nas comunidades negras 
Uma das estratégias corriqueiras dos entrevistados consiste em transformar este imaginário em atributo positivo (Agler, 1992), invertendo a relação de dominação. Suas habilidades para a dança e a música se transformam, assim, nas "características joviais da raça", como dizem alguns deles e em uma fonte de superioridade no domínio corporal. Este recurso, mobilizado por outros grupos dominados através da história [...] é o que Michel Agier chama de a utilização "[d]as homologiuas formais de inversão e supernaturalização da identidade" (VIGOYA, 2018, pp. 111-112).

De forma análoga, Lucas Veiga aponta uma questão parecida ao abordar a situação das "bixas pretas" na "economia do desejo":

O não-lugar da bixa preta na economia do desejo é o lugar de um corpo, por vezes animalizado, em que a fantasia em torno do tamanho do pênis e de sua performance sexual preenche o imaginário das bichas brancas, deixando pouco espaço para que a bixa preta possa entrar na economia do desejo como sujeito que tem um corpo e não apenas um corpo. Os movimentos lgbts são ainda muito atravessados pela supremacia branca e pelo racismo dela derivado, de modo que pessoas lgbts negras, mesmo nestes espaços mais plurais, em que se pressupõe o acolhimento a todos que possuem uma sexualidade desviante da cis-hetero-norma, experienciem a recusa dos membros brancos dessas comunidades de reconhecerem seus privilégios enquanto tais e de se engajarem numa luta lgbt que seja interseccional (VEIGA, 2019, p. 88).

É preciso atentar, como chama a atenção Veiga para as diferenças entre bichas brancas e bichas pretas. O recorte racial, ou o movimento de racialização do termo, se faz mister para que possamos entender esses processos. É preciso enfrentar a discussão sobre a questão racial no Brasil e a maneira pela qual produz, informa e lê os corpos negros. Faço esse movimento com objetivos analíticos e muita cautela, visto que não se trata de uma equação "ser bicha + ser preta/o" ou "ser homossexual + ser preto", já que ser bicha/homossexual informa profundamente a maneira pela qual se vivencia a dimensão racial ao passo que há um profundo movimento de racialização da experiência de ser bicha. Conforme afirma Osmundo Pinho:

[...] no mundo real os sujeitos se produzem através da interseção de diferenças e desigualdades diversas. A interseção ou combinação dessas diferenças produz novas diferenças, então, não é apenas uma soma, ou seja, uma bicha preta não é um sujeito que acumula duas identidades, é outra posição diferente que é produzida através dessa interação ou dessa confluência. Essas diferenças reagem e se relacionam com outras desigualdades e produzem novas alternativas políticas (PINHO, 2004, p.129).

\section{REFERÊNCIAS BIBLIOGRÁFICAS}

ABREU, Martha; DANTAS, Carolina Vianna; MATTOS, Hebe (org.). Histórias do pós-abolição no mundo atlântico: identidades e projetos políticos - volume 1. Niterói: Editora da UFF, 2014. 
BORRILLO, Daniel. "A homofobia”. In: LIONÇO, Tatiana; DINIZ, Debora. "Homofobia e Educação". LetrasLivres, 2009. Disponível em: https://hal.archives-ouvertes.fr/hal01242485/document

BLOCH, Marc. "A apologia da história ou ofício do historiador". Rio de Janeiro: Jorge Zahar, 2001.

ALBUQUERQUE, Wlamyra. "A exaltação das diferenças: racialização, cultura e cidadania negra (Bahia, 1880 - 1900)”. 2004. Tese (Doutorado) - UFBA, Bahia.

ALBUQUERQUE, Wlamyra. "A vala comum da 'raça emancipada': abolição e racialização no Brasil, breve comentário”. História Social, n. 19, segundo semestre de 2010

BURKE, Peter (org.). "A escrita da história: novas perspectivas". São Paulo: Editora UNESP, 1992.

CARNEIRO, Sueli. "Enegrecer o feminismo: a situação da mulher negra na América Latina a partir de uma perspectiva de gênero". Publicado em 6 de março de 2011. Disponível em: http://arquivo.geledes.org/br/em-debate/sueli-carneiro/17473-suelicarneiro-enegrecer-

ofeminismo-a-situacao-da-mulher-negra-na-america-latina-apartir-de-uma-perspectiva-degenero

CERQUEIRA, Daniel; LIMA, Renato Sergio; BUENO, Samira et. al. "Atlas da Violência 2017". Ipea e FBSP. Disponível http://www.ipea.gov.br/portal/images/170602_atlas_da_violencia_2017.pdf

CONNELL, Raewynn. “Masculinites”. Berkeley, Calif: University of California Press, 2005

COSTA, Emilia Viotti da. “A Abolição”. São Paulo: Editora UNESP, 2010

CRENSHAW, Kimberlé. "Documento para o encontro de especialistas em aspectos da discriminação racial relativos ao gênero. Estudos Feministas, Florianópolois, v.10, n.1, 2002, pp. $171-188$

CUNHA, Olivia Maria Gomes da. "1933: um ano em que fizemos contato". Revista USP, 1996, São Paulo (28): pp. 142-163.

CUSTÓDIO, Túlio. "Per-vertido Homem Negro: reflexões sobre masculinidades negras a partir de categorias de sujeição". In: RESTIER, Henrique; SOUZA, Rolf Malungo (org). "Diálogos contemporâneos sobre homens negros e masculinidades" - São Paulo: Ciclo Contínuo Editorial, 2019.

DAVIS, Angela. "As mulheres negras na construção de uma nova utopia." Conferência realizada na $1^{\text {a }}$ Jornada Cultural Lélia Gonzalez. São Luiz, 13 de dez. Disponível em: www.geledes.org.br/as-mulheres-negras-na-construcao-de-uma-nova-utopia-angeladavis/\#gs._kSJASA>

DAVIS, Angela. "Mulheres, raça e classe”. São Paulo: Boitempo, 2016

DOUGLAS, Mary. Pureza e Perigo. "Ensaio sobre as noções de Poluição e Tabu". Lisboa, Edições 70 (col. Perspectivas do Homem, n. ${ }^{\circ} 39$ ), s.d. (trad. por Sônia Pereira da Silva, 1966). 
ENGEL, Magali. "História e Sexualidade" In: CARDOSO, Ciro Flamarion; VAINFAS, Ronaldo (orgs.). "Domínios da História: ensaios de teoria e metodologia". Rio de Janeiro: Campus, 1997

FREIRE, Lucas de Magalhães. De sodomitas a homossexual: a construção de uma categoria social no Brasil. Revista Habitus: revista eletrônica dos alunos de graduação em Ciências Sociais - IFCS/UFRJ, Rio de Janeiro, v. 10, n. 1, p. 88 - 100, agosto. 2012. Semestral.

GREEN, James. "Além do carnaval: A homossexualidade masculina no Brasil do século XX. São Paulo: Editora UNESP, 2000.

GRUPO GAY DA BAHIA. "Relatório 2016. Assassinatos LGBT no Brasil". Disponível em: https://homofobiamata.files.wordpress.com/2017/01/relatc3b3rio-2016-ps.pdf

GUIMARÃES, Antônio Sergio Alfredo. "Como trabalhar raça em sociologia". Educação e Pesquisa: São Paulo, v. 29, n. 1, pp. 93-107, jan/jun 2003.

GUIMARÃES, Germana G.; ROCHA, Solange P. "Representações e visões de pessoas negras na literatura de cordel: um exercício em sala de aula para visualizar e superar imaginários racistas no pós-abolição (1888-1930)" In: XAVIER, Giovana. "Histórias da Escravidão e do Pós-Abolição para as escolas". Cruz das Almas: EDUFRB; Belo Horizonte: Fino Traço, 2016.

JARDIM, Suzane. "Reconhecendo estereótipos racistas na mídia norte-americana". 2016. Disponível em: https://medium.com/@suzanejardim/alguns-estere\%C3\%B3tipos-racistasinternacionais-c7c $7 \mathrm{bfe} 3 \mathrm{dbf} 6$

MAIO, Marcos Chor; SANTOS, Ricardo Ventura (orgs.). "Raça como questão: História, Ciência e Identidades no Brasil". Rio de Janeiro: Editora FIOCRUZ, 2010

MATTOS, Hebe; RIOS, Ana Lugão. "O pós-abolição como problema histórico: balanços e perspectivas. Topoi, v.5, n. 8, jan-jun 2004, pp. 170-198

MOTT, Luiz. "Homo-afetividades e direitos humanos". Estudos Feministas: Florianópolis, 14(2): 248, maio-agosto/2006

MUNANGA, Kabengele. "Uma abordagem conceitual das noções de raça, identidade e etnia". Palestra proferida no $3^{\circ}$ Seminário Nacional Relações Raciais e Educação-PENESB-RJ, 05/11/03.

MUNANGA, Kabengele. "Rediscutindo a Mestiçagem no Brasil: identidade nacional versus identidade negra". Belo Horizonte, Autêntica, 2008.

PEREIRA, Amilcar. "O mundo negro: relações raciais e a constituição do movimento negro contemporâneo no Brasil”. Rio de Janeiro: Pallas: FAPERJ, 2013.

PINHO, O. S. A. A Guerra dos Mundos Homossexuais - resistência e contra hegemonias de raça e gênero. In: Luis Felipe Rios; Vagner de Almeida; Richard Parker; Cristina Pimenta; Veriano Terto Jr. (Org.). Homossexualidade: produção cultural, cidadania e saúde. Rio de Janeiro: Associação Brasileira Interdisciplinar de Aids, 2004, v. 1, p. 01-196

PINTO, Matheus Rodrigues. "Reconstruindo as muralhas de Sodoma - Homossexualidade no mundo afro-brasileiro no século XVII". Dissertação (Mestrado). UFF, 2015 
RATTS, Alex. "Entre personas e grupos homossexuais negros e afro-LGBTTS" In: BARROS JÚNIOR, Francisco de Oliveira; LIMA, Solimar Oliveira (orgs)."Homossexualidade sem fronteiras". Rio de Janeiro: Booklinks/Teresina: Grupo Matizes, 2007

REDUZINO, Rodrigo Antônio. De João Francisco dos Santos à Madame Satã: Análise da incorporação do Racismo Científico do século XIX pelas instituições brasileiras. Dissertação de Mestrado (PPGS-UFF), 2017.

SCHWARCZ, Lilia M. "O espetáculo das raças: cientistas, instituições e questão racial no Brasil 1870-1930”. São Paulo: Companhia das Letras, 1993.

SKIDMORE, Thomas E. "Preto no branco - Raça e nacionalidade no pensamento brasileiro". São Paulo: Companhia das Letras, 2012

TAVARES, Rodolfo Souza. "A inversão sexual da ordem heteronormativa: discurso médico sobre homens homossexuais e mulheres lésbicas no Rio de Janeiro (1870-1935)". Trabalho de Conclusão de Curso. UFF, 2017.

TRUTH, Sojourner. “Ain't I A Woman?”. Discurso proferido na Convenção das mulheres de Akfron. Ohio: 1851. Disponível em: https://schools.nyc.gov/NR/rdonlyres/E151FA9D-60174556-981F-CD076D731A72/0/SecondaryTextGuideAnswerKeyAintWoman.pdf

VEIGA, Lucas. "Além de preto é gay: as diásporas da bixa preta". In: RESTIER, Henrique; SOUZA, Rolf Malungo (org). "Diálogos contemporâneos sobre homens negros e masculinidades" - São Paulo: Ciclo Contínuo Editorial, 2019.

VIGOYA, Mara Viveros. As cores da masculindiade: experiências interseccionais e práticas de poder na Nossa América - Rio de Janeiro (RJ): Papéis Selvagens, 2018

VIANNA, Larissa. "Gonçalo Garcia: identidades e relações raciais na história de um santo pardo na América portuguesa" In: COTTIAS, Myriam; MATTOS, Hebe. "Escravidão e Subjetividades no Atlântico luso-brasileiro e francês (Séculos XVIII - XIX). Disponível em: http://books.openedition.org/oep/778 